Bull. Chem. Soc. Ethiop. 2014, 28(2), 161-176.

Printed in Ethiopia

ISSN 1011-3924

DOI: http://dx.doi.org/10.4314/bcse.v28i2.1

(C) 2014 Chemical Society of Ethiopia

\title{
LEAD ACCUMULATION IN THE ROADSIDE SOILS FROM HEAVY DENSITY MOTOR WAY TOWNS OF EASTERN ETHIOPIA
}

\author{
Endale Teju ${ }^{1,2}$, Negussie Megersa ${ }^{1, *}$, Bhagwan Singh Chandravanshi ${ }^{1}$ and Feleke Zewge ${ }^{1}$ \\ ${ }^{1}$ Department of Chemistry, Addis Ababa University, P. O. Box 1176, Addis Ababa, Ethiopia \\ ${ }^{2}$ Department of Chemistry, Haramaya University, P.O. Box 138, Dire Dawa, Ethiopia
}

(Received March 22, 2013; revised January 27, 2014)

\begin{abstract}
The levels of lead pollution in the roadside soils of the heavy density motor ways of Eastern Ethiopia, in particular; Modjo, Bishoftu and Adama towns were studied. Soil samples were collected from a total of 22 sampling sites while the control samples were obtained from places about $1 \mathrm{~km}$ away from the main roads of each town. Concentrations of lead, in soil samples, were determined using flame atomic absorption spectrometer and the average concentrations of lead were found to be $93.3 \pm 1.0,79.4 \pm 0.6$ and $80.6 \pm 0.4 \mu \mathrm{g} / \mathrm{g}$ for Modjo, Bishoftu and Adama towns, respectively. The concentrations of lead in soils sampled $1 \mathrm{~km}$ away from the main road for each town were: $13.5 \pm 0.3,19.6 \pm 0.7$ and $20.8 \pm 0.8 \mu \mathrm{g} / \mathrm{g}$ for Modjo, Bishoftu and Adama towns, respectively. The contamination factors for the average lead concentrations of Modjo, Bishoftu and Adama towns were $6.9,4.0$ and 3.8, respectively. Besides, the correlations between the lead level and the traffic density of the corresponding roads were found to be $\mathrm{r}(4)=0.82, \mathrm{p}<0.05$ for Modjo, $\mathrm{r}(5)=0.32, \mathrm{p}<0.05$ for Bishoftu and $\mathrm{r}(9)=0.81, \mathrm{p}<0.05$ for Adama.
\end{abstract}

KEY WORDS: Gasoline, Lead, Roadside soils, Traffic density, Vehicular emission, Ethiopia

\section{INTRODUCTION}

Global industrialization and human social and agricultural activities have significant effects on environmental pollution and the global ecosystem which, in turn, have undesirable effects on human health and other living organisms [1]. Environmental pollution could be due to the organic and inorganic pollutants [2,3]. Inorganic chemical pollutants are naturally found at trace levels in soil and vegetation but, due to different anthropogenic sources these pollutants are often concentrated in the environmental compartments. Generally, inorganic chemicals could be considered as nutrients and heavy metals [4]. Heavy metals are not biodegradable and thus persist in the environment for long periods of time and their effect is dependent on their corresponding concentrations $[1,5]$.

Because of the different industrial activities that are causing wide distribution of lead, it is ubiquitous in the environment today. The major environmental sources of metallic lead are paints, auto-exhausts and contaminated water and food [6]. The use of gasoline containing lead as additives, as the cheapest sources of octane, is known to be one of the major sources of lead in the environment [7]. Adverse occupational hazard, however, is prevalent to the workers that are most frequently exposed to the lead that are released from several manufacturing and processing industries including the lead smelter and refineries, battery, painting, ceramic and printing workshops. Moreover, the hazard may also extend to the people exposed to the contaminated food, water and environment [8].

Lead is one of the most common inorganic pollutants in the environment and especially dangerous for unborn and young children causing various illnesses and in particular affect the performances of the central nervous system [9]. Lead is known to induce a wide range of biochemical and physiological dysfunctions to humans and laboratory animals. Recent epidemiological studies have revealed that increased level of lead in the blood has an

${ }^{*}$ Corresponding author. E-mail: megersane@yahoo.com 
association with several disease outcomes such as hypertension, peripheral artery diseases, kidney diseases, neurodegenerative diseases and cognitive impairments [10-12]. Lead exposure is also implicated in a broad clinical spectrum of disease, including hematological, renal, cardiovascular, neurological, developmental and behavioral disorders [13].

Burnt petrol from motor vehicles releases significant quantities of sulfur dioxide, oxides of nitrogen, carbon monoxide, lead and suspended particulate matters [14]. Among these residues released to the environment by the vehicular emission, lead commonly resides on the roadside soils and has got several routes to express its effect on humans and plants around the highways. It persists on the roadside soils being adsorbed to the soil particles or can be translocated by wind and runoff and eventually join the nearby water bodies [1]. Although lead naturally occurs in soils in relatively low concentrations, the quantity in the environment has been increasing for several centuries due to human activities particularly the use of lead additives in gasoline [15]. Lead contamination of roadside soils is generally attributed to the exhaust emissions of automobiles operating with leaded gasoline [16]. Studies revealed that lead is routinely released into the atmosphere by the burning of lead alkyls in petrol while on a global scale to a much lesser degree from industrial processes such as lead smelting, iron and steel production and coal combustion [17]. The high concentrations of lead and cadmium contained in soils and vegetables from 12 towns of Poland were attributed to vehicular emissions [18].

Furthermore, literature reports confirmed that leaded gasoline was responsible for the lead pollution of the roadside soils and as a result, countries were forced to decrease the levels of lead in gasoline. Before 1981, lead in gasoline in Hong Kong averaged about $0.84 \mathrm{~g} \mathrm{~L}^{-1}$. Then the lead content was gradually reduced and by early 1987 to $0.25 \mathrm{~g} \mathrm{~L}^{-1}$ [19]. Countries in North America, Europe, Japan and Asia have phased out leaded gasoline; about $85 \%$ of the total gasoline consumption today is lead free. However, according to the World Bank report, there were a number of countries that use lead additives to boost octane levels in gasoline till the year 2003. Most of these countries are from African region and the Middle East. In this regard, the market share of leaded gasoline used in Ethiopia in the year 2002 was $100 \%$ with maximum concentrations of $0.6 \mathrm{~g} \mathrm{~L}^{-1}$ of lead, while during the earlier years, e.g., in 1999, the concentration of lead in the gasoline was $0.76 \mathrm{~g} \mathrm{~L}^{-1}$. Finally, Ethiopia started importing unleaded gasoline at the beginning of the year 2004 [20].

Vehicular emission is generally the largest source of lead exposure in many urban areas, often accounting for more than 90 percent of all atmospheric emissions [14]. Literature reports have also revealed that lead is a toxic heavy metal associated with a number of health problems to individuals exposed to it [6,10-13]. However, there was no previous study carried out to understand the levels to which the roadside soils of the eastern towns of Ethiopia; namely, Bishoftu, Modjo, and Adama towns were polluted by lead accumulation originated from the heavy vehicular densities. Hence, this study was initiated to investigate the extent to which the roadside soils of these three towns are polluted by lead contaminations released from vehicular exhausts.

\section{EXPERIMENTAL}

\section{Reagents and standards}

High-purity analytical grade reagents were used in this study. Concentrated $\mathrm{HNO}_{3}(69-72 \%$, Spectrosol BDH, UK), concentrated $\mathrm{HCl}$ (36-38\%, Hopkins and Williams, UK) and $\mathrm{H}_{2} \mathrm{O}_{2}(21$ $31 \%$ Alvetra $\mathrm{GmbH}$, Germany) were used for digestion of the soil samples. $1000 \mathrm{mg} / \mathrm{L}$ standard lead solution was obtained from Buck Scientific (PuroGraphic ${ }^{\mathrm{tm}}$ calibration standard, Buck Scientific, USA). Intermediate standard solutions of 100 and $10 \mathrm{mg} / \mathrm{L}$ were prepared each time by dilution of the stock standard solution with deionized water. A series of working standard 
solutions at four concentration levels, i.e., 0.5, 2.0, 3.0 and $6.0 \mathrm{mg} / \mathrm{L}$, were prepared freshly by appropriately diluting the intermediate standards, for plotting the calibration graphs.

\section{Instrumentation}

Determinations of lead in the soil samples were carried out using Buck Scientific 210VGP Flame Atomic Absorption Spectrometer (FAAS) (Norwalk, U.S.A.). The pH of the soil samples was measured utilizing WTW Inolab pH/ION Level $2 \mathrm{pH}$ meter (Germany) and Thermo Orion conductivity meter Model 145 (Germany) was utilized for measurement of the electrical conductivities.

\section{Study areas}

The three studied towns are located in the Oromia Regional State and south east of Addis Ababa, the capital city of Ethiopia. These towns are serving as the confluence point to all trucks and public transports directing to the east, south and further south eastern towns of the country. All goods meant for the export as well as import are also transported via the roads passing by these towns, to the seaports of Djibouti. Furthermore, the Addis Ababa-Djibouti railroad used to run via these towns until recently. Therefore, it is very likely that the roadside soils of these towns are greatly affected by the lead pollution originated from the anthropogenic sources particularly, from vehicular emission.

The geographical location of Bishoftu, the nearest town to Addis Ababa (47 km), is at a latitude and longitude of $8^{\circ} 45^{\prime} \mathrm{N}$ and $38^{\circ} 59^{\prime} \mathrm{E} / 8.75^{\circ} \mathrm{N}$ and $38.983^{\circ} \mathrm{E}$, respectively, with an elevation of 1920 meters above sea level. A total of six sampling sites were investigated from this town (Figure 1). Modjo is found between Bishoftu and Adama and is $75 \mathrm{~km}$ away from Addis Ababa. It is located at a latitude and longitude of $8^{\circ} 39^{\prime} \mathrm{N} 39^{\circ} 5^{\prime} \mathrm{E} / 8.65^{\circ} \mathrm{N} 39.083^{\circ} \mathrm{E}$, respectively, with elevations between 1788 and 1825 meters above sea level. The five sampling sites considered in this town are shown in Figure 2. Adama, on the other hand, is situated at the base of the Western Rift Valley escarpment and is rather the busiest transport center than Bishoftu and Modjo. It is located at a latitude and longitude of $8.55^{\circ} \mathrm{N}$ and $39.27^{\circ} \mathrm{E}$, respectively, at an elevation of 1712 meters above sea level and is $99 \mathrm{~km}$ southeast of Addis Ababa. Ten sampling sites were considered in Adama town which are given in Figure 3.

\section{Sample collection and pretreatment}

Soil samples were randomly collected from mid-January to the end of February, 2009, along the major roads of the three towns, avoiding areas with obvious signs of disturbance such as animal burrowing and landfills. At each site, three holes of about $30 \mathrm{~cm}^{2}$ were dug and $0.5 \mathrm{~kg}$ soil was taken [21]. In order to obtain a composite sample from each hole, the soil cross sections were cut down to $15 \mathrm{~cm}$ using hand driven stainless steel shovel, and the samples from the three holes were mixed together. The mixed and homogenized portions of the samples were brought to the laboratory being packed in polyethylene bags and air dried for two days. Then, the samples were ground using mortar and pestle and sieved with $0.09-\mathrm{mm}$ mesh size sieve. Finally, the sieved samples were kept packed until taken out for analysis. Similarly, soil samples for the control groups were taken from mountainous areas covered with trees which are far away (1 $\mathrm{km})$ from the traffic flow. These samples were also treated in a similar manner as the other samples [22]. 


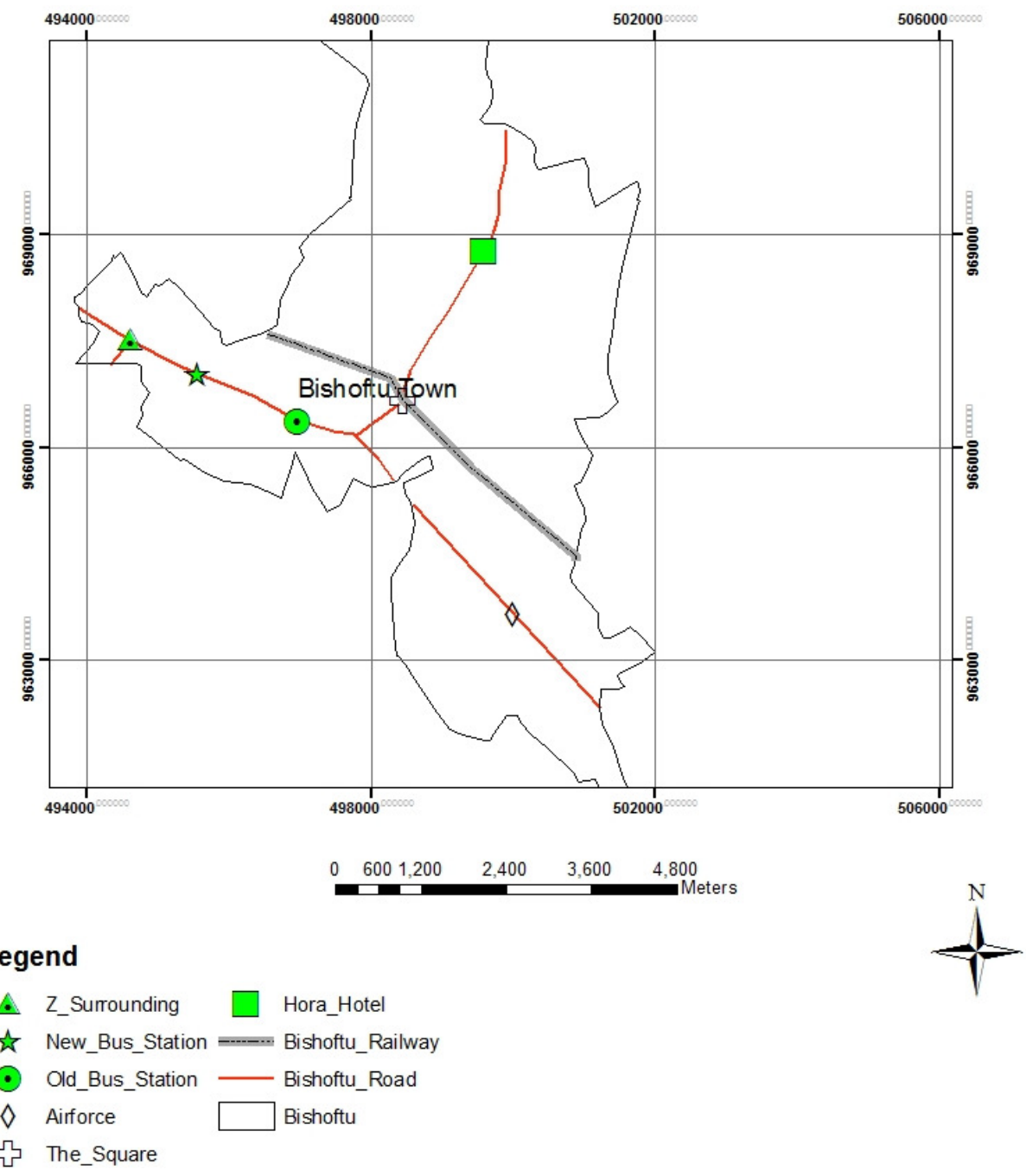

Figure 1. Map of Bishoftu town showing the location of the six sampling sites. 
$\mathrm{Pb}$ accumulation in roadside soils from heavy density motor way towns of eastern Ethiopia 165

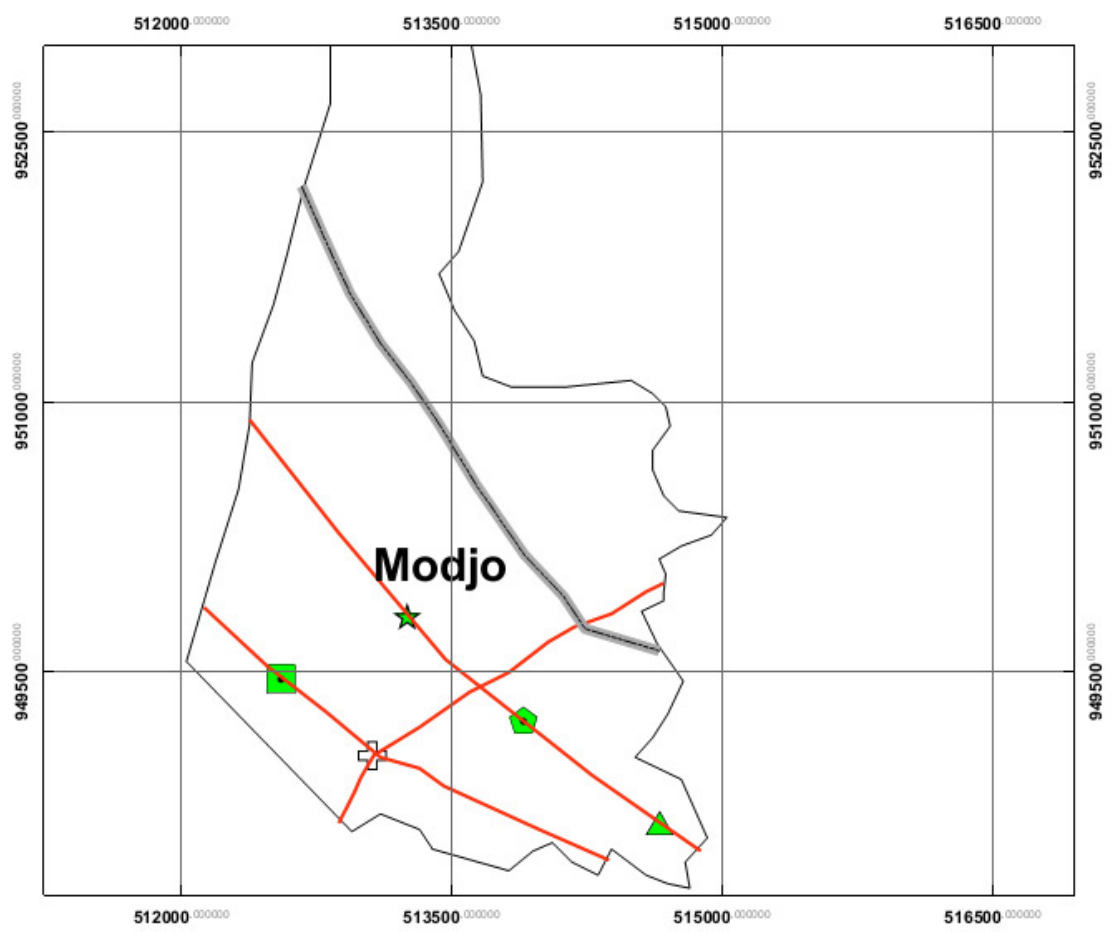

\section{Legend}

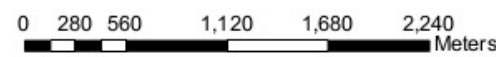

$$
\begin{aligned}
& \text { - Modjo_Bus_Station } \\
& \text { 乌 Square_to_Ziway } \\
& \triangle \text { Modjo_Total } \\
& \text { - Ethio_Japan_Textile } \\
& \text { \. Modjo_Market } \\
& \text { _-_Modjo_Railway } \\
& \text { — Modjo_Road } \\
& \text { Modjo }
\end{aligned}
$$

Figure 2. Map of Modjo town showing the location of the five sampling sites. 


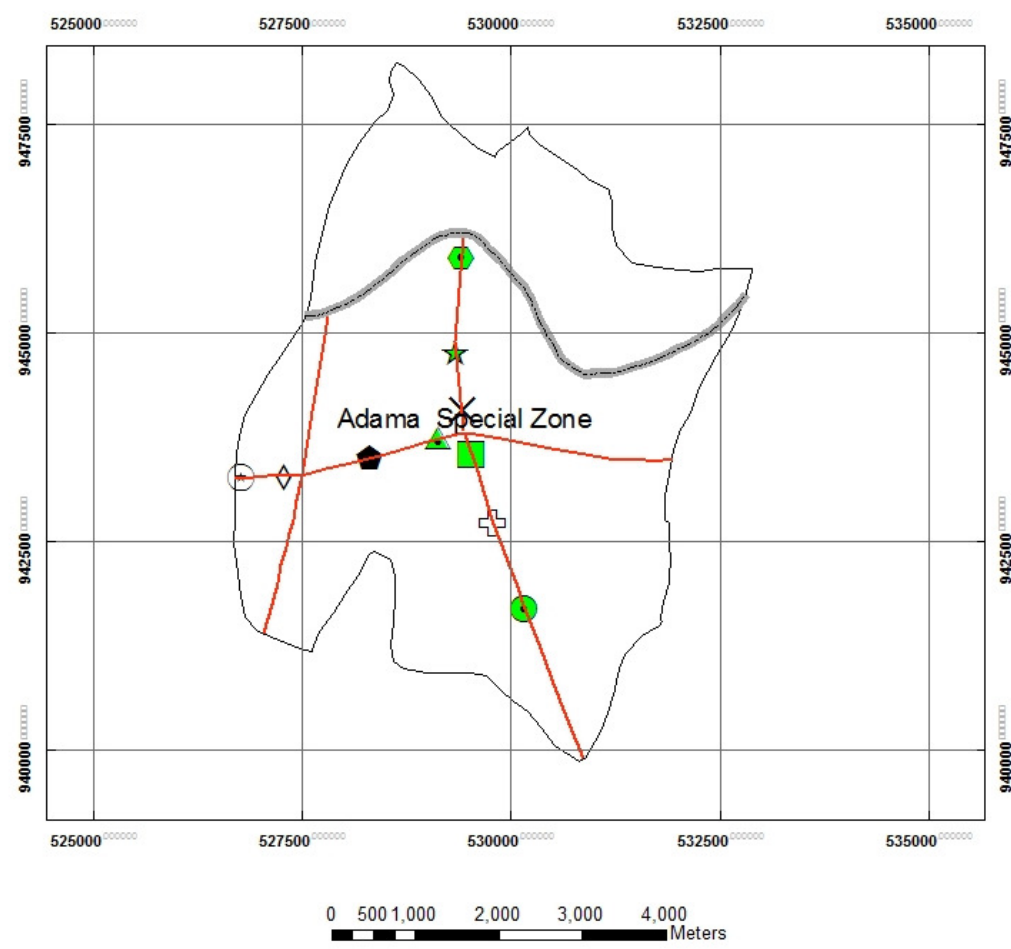

\section{Legend}

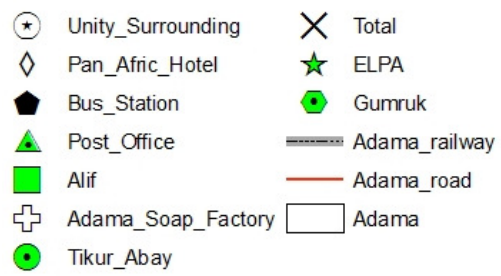


Determination of $\mathrm{pH}$ and electrical conductivity

Accurately weighed $10 \mathrm{~g}$ of the ground and sieved soil sample was weighed in each of the five $50 \mathrm{~mL}$ clean glass beakers and $25 \mathrm{~mL}$ deionized water was added to form a 1:2.5 soil/water slurry solution. Then, the beakers, containing the mixture, were placed on an automatic stirrer and stirred for $30 \mathrm{~min}$. For measurement of $\mathrm{pH}$, the meter was calibrated with the standard buffer solutions of $\mathrm{pH} 4$ and 7 before use. The $\mathrm{pH}$ and the electrical conductivity measurements of the soil/water mixtures were carried out immediately after the soil samples were brought to the laboratory. The measurements were done by immersing the calibrated $\mathrm{pH}$ and conductivity meter probes into the upper part of the slurry solution of the mixtures until the readings were stable [25].

\section{Recovery and precision studies}

Digestion of the soil samples was carried out using $\mathrm{HNO}_{3}-\mathrm{HCl}$ mixture followed by further treatment with $\mathrm{H}_{2} \mathrm{O}_{2}$, and the final determination of lead in the filtered solutions was performed using FAAS. In order to evaluate the performance of the analytical technique used, for quantitative extraction of lead from the soil samples, known amounts of the standard of lead was spiked to the processed bulk of the soil samples. The soil were then undergone the appropriate digestion procedure followed by filtration, dilution and final analyte determination.

\section{Instrumental parameters of the FAAS}

The wavelength and the slit width of the FAAS were selected and adjusted at the beginning of the analysis and were kept constant throughout the analysis periods. The instrumental parameters of the FAAS, used for the determination of the concentrations of lead, are described in Table 1.

Table 1. Instrumental parameters of FAAS during analysis of lead.

\begin{tabular}{|l|l|}
\hline Instrumental parameters & Corresponding value (condition) \\
\hline Energy & $3.65 \times 10^{-7} \mathrm{~J}$ \\
\hline Wavelength & $283.1 \mathrm{~nm}$ \\
\hline Slit width & $0.7 \mathrm{~nm}$ \\
\hline Fuel & Air-acetylene $(99 \%$ purity) \\
\hline Flam type & Lean blue \\
\hline Detection limit & $0.1 \mathrm{mg} / \mathrm{L}$ \\
\hline Sample introduction system & Direct aspiration $(8 \mathrm{~mL} / \mathrm{min})$ \\
\hline Radiation source & Hollow- Cathode Lamp $(\mathrm{HCL})$ \\
\hline
\end{tabular}

\section{RESULTS AND DISCUSSION}

\section{Performance of the analytical instrument}

The FAAS used in the current study was evaluated, for its performance, by constructing a calibration curve, which was achieved by plotting the instrumental response as a function of concentration of the analyte [26]. Quantitative determination of lead in the processed samples was carried out utilizing the linear relationship established from a series of standard solutions or the calibration curve. In the current study, linearity was obtained in the range of $0.5-6 \mathrm{mg} / \mathrm{L}$, at four points. The linear equation relating the instrument response to the varied concentrations of 
the standards was given by: $\mathrm{Y}=0.0653 \mathrm{X}-0.0008$, where $\mathrm{X}$ is in $\mathrm{mg} / \mathrm{L}$. Furthermore, the coefficient of determination $\left(\mathrm{r}^{2}\right)$ was found to be 0.9990 .

\section{Method detection limits (MDL)}

Detection limit of the analytical method employed in the present study was calculated using the data obtained by analyzing the reagent blank. Five reagent blanks were analyzed, each in triplicate, and the standard deviation was calculated from 15 determinations. Then, the method detection limit was obtained by multiplying the standard deviation obtained for the blanks by 3 [27]. The method detection limit determined for the method used in the current analysis was found to be $0.12 \mathrm{mg} / \mathrm{L}$. It has thus been noted that the value determined for MDL is higher than the instrument detection limit of the FAAS, which is $0.10 \mathrm{mg} / \mathrm{L}$.

\section{Levels of lead in the roadside soils of Bishoftu, Modjo and Adama Towns}

The average lead contents of all the soil samples, for the three towns, were found to be more than threefold of the background lead concentrations determined for their respective control samples, though the mean contents of lead were below $100 \mu \mathrm{g} / \mathrm{g}$, the maximum recommended value of lead in soil by WHO [28]. The concentrations of lead in the roadside soils of Modjo, Bishoftu and Adama towns are summarized in Tables 2, 3 and 4, respectively. For the soil samples from Modjo town, the lowest and highest concentrations of lead were $86.6 \pm 0.1$ and $105 \pm 1.1 \mu \mathrm{g} / \mathrm{g}$, corresponding to Modjo Bus Station (mid-town) and the Square to Ziway (south of Modjo town), respectively (Table 2).

Similarly, the minimum and maximum levels of lead, for soils of Bishoftu sites, were found to be $56.9 \pm 1.2$ and $109 \pm 0.7 \mu \mathrm{g} / \mathrm{g}$ around the new (western side of the town) and old (eastern side of the town) bus stations, respectively (Table 3 ).

On the other hand, the minimum and maximum concentrations of lead for the soil samples from Adama town were $41.5 \pm 0.5$ and $134 \pm 1.1 \mu \mathrm{g} / \mathrm{g}$ at the sites Adama Soap Factory of Asela road (southeast of the town) and Post Office of Derartu Tulu Avenue (mid-town), respectively (Table 4).

Table 2. Concentrations of lead in the roadside soils in Modjo town.

\begin{tabular}{|c|c|c|c|c|c|c|c|c|}
\hline 疍 & Sample sites & $\begin{array}{l}\text { Sample } \\
\text { code }\end{array}$ & \begin{tabular}{|c} 
Distance \\
$(\mathrm{m})^{\mathrm{a}}$
\end{tabular} & $\begin{array}{c}\text { Traffic density } \\
\text { (No Car/h) } \\
\bar{X} \text { (range) }\end{array}$ & $\begin{array}{c}\mathrm{pH} \\
\left(25^{\circ} \mathrm{C}\right)\end{array}$ & $\begin{array}{l}\text { Cond. }(\mu \mathrm{S}) \\
\bar{X} \pm \text { ts } \sqrt{N} \\
\left(25^{0} \mathrm{C}\right)^{\mathrm{b}}\end{array}$ & $\begin{array}{c}{[\mathrm{Pb}]} \\
\bar{X}_{(\mu \mathrm{g} / \mathrm{g})^{\mathrm{b}}} \pm \mathrm{ts} \sqrt{\mathrm{N}}\end{array}$ & $\begin{array}{c}\text { Average [Pb] } \\
\bar{X} \pm \mathrm{ts} \sqrt{ } \mathrm{N} \\
(\mu \mathrm{g} / \mathrm{g})^{\mathrm{b}}\end{array}$ \\
\hline \multirow{6}{*}{$\stackrel{\circ}{\stackrel{\circ}{8}}$} & Bus Station & MJ-1 & 1.5 & $\begin{array}{c}593 \\
(498-687)\end{array}$ & $7.13 \pm 0.11$ & $4000 \pm 9.7$ & $88.0 \pm 0.7$ & \multirow{6}{*}{$93.3 \pm 1.3$} \\
\hline & Total & MJ-2 & 1.0 & $\begin{array}{c}480 \\
(397-537)\end{array}$ & $7.15 \pm 0.16$ & $1899 \pm 10.4$ & $86.6 \pm 0.1$ & \\
\hline & \begin{tabular}{|l|} 
Square to \\
Ziway
\end{tabular} & MJ-3 & 0.5 & $\begin{array}{c}1726 \\
(1621-1863)\end{array}$ & $7.31 \pm 0.21$ & $306 \pm 6.5$ & $105 \pm 1.1$ & \\
\hline & \begin{tabular}{|l|} 
Ethio-Japan \\
Textile \\
\end{tabular} & MJ-4 & 0.5 & $\begin{array}{c}502 \\
(479-532) \\
\end{array}$ & $7.21 \pm 0.12$ & $1724 \pm 7.6$ & $86.9 \pm 0.5$ & \\
\hline & \begin{tabular}{|l|} 
Modjo \\
Market
\end{tabular} & MJ-5 & 1.0 & $\begin{array}{c}614 \\
(573-641)\end{array}$ & $7.18 \pm 0.15$ & $1902 \pm 5.3$ & $99.8 \pm 0.4$ & \\
\hline & Control & $\mathrm{C}-1$ & 1000 & - & $7.06 \pm 0.14$ & $284 \pm 6.2$ & $13.5 \pm 0.3$ & \\
\hline
\end{tabular}

${ }^{a}$ The distance is measured from the edge of the main road to the sampling points. ${ }^{\mathrm{b}}$ Results are calculated at $95 \%$ confidence interval using the t-test $(\mathrm{t})$ and the standard deviation (s) for the mean $(\bar{X})$ of a triplicate analysis $(\mathrm{N})$. 
$\mathrm{Pb}$ accumulation in roadside soils from heavy density motor way towns of eastern Ethiopia 169

Table 3. Concentrations of lead in the roadside soils of Bishoftu town.

\begin{tabular}{|c|c|c|c|c|c|c|c|c|}
\hline$\underbrace{\tilde{3}}_{0}$ & Sample sites & $\begin{array}{l}\text { Sample } \\
\text { code }\end{array}$ & $\begin{array}{c}\text { Distance } \\
(\mathrm{m})^{\mathrm{a}}\end{array}$ & $\begin{array}{c}\text { Traffic density } \\
\text { (No Car/h) } \\
\bar{X} \text { (range) }\end{array}$ & $\begin{array}{c}\mathrm{pH} \\
\left(25^{\circ} \mathrm{C}\right)\end{array}$ & $\begin{array}{l}\text { Cond. ( } \mu \mathrm{S}) \\
\bar{X} \pm \mathrm{ts} \sqrt{\mathrm{N}} \\
\left(25^{0} \mathrm{C}\right)^{\mathrm{b}}\end{array}$ & $\frac{[\mathrm{Pb}]}{X} \pm \mathrm{ts}_{(\mu \mathrm{g} / \mathrm{g})^{\mathrm{b}}}$ & $\begin{array}{c}\text { Average [Pb] } \\
\bar{X} \pm \text { ts } \sqrt{ } \mathrm{N} \\
(\mu \mathrm{g} / \mathrm{g})^{\mathrm{b}}\end{array}$ \\
\hline \multirow{7}{*}{ 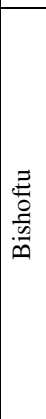 } & Hora Hotel & BS-1 & 1 & $\begin{array}{c}389 \\
(349-438)\end{array}$ & $7.70 \pm 0.19$ & $422 \pm 4.2$ & $58.8 \pm 1.7$ & \multirow[t]{2}{*}{$72.7 \pm 0.4$} \\
\hline & The Square & BS-2 & 0.5 & $\begin{array}{c}912 \\
(889-953) \\
\end{array}$ & $7.59 \pm 0.12$ & $2700 \pm 5.7$ & $86.5 \pm 0.2$ & \\
\hline & Air force & BS-3 & 2 & $\begin{array}{c}1767 \\
(1680-1794)\end{array}$ & $7.74 \pm 0.17$ & $676 \pm 11.9$ & $95.7 \pm 1.4$ & \multirow{4}{*}{$82.7 \pm 0.5$} \\
\hline & \begin{tabular}{|l} 
Old Bus \\
Station
\end{tabular} & BS-4 & 1 & $\begin{array}{c}1947 \\
(1863-1967)\end{array}$ & $7.14 \pm 0.16$ & $1095 \pm 9.7$ & $109 \pm 0.7$ & \\
\hline & \begin{tabular}{|l|} 
New Bus \\
Station
\end{tabular} & BS-5 & 2.5 & $\begin{array}{c}1928 \\
(1856-1940)\end{array}$ & $7.49 \pm 0.22$ & $384 \pm 6.0$ & $56.9 \pm 1.2$ & \\
\hline & \begin{tabular}{|l|}
$Z$. \\
Surrounding \\
\end{tabular} & BS-6 & 1.5 & $\begin{array}{c}1947 \\
(1890-1971)\end{array}$ & $7.40 \pm 0.23$ & $554 \pm 7.4$ & $69.6 \pm 0.4$ & \\
\hline & 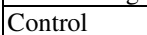 & & 0 & & & & & \\
\hline
\end{tabular}

${ }^{\mathrm{a}}$ The distance is measured from the edge of the main road to the sampling points. ${ }^{\mathrm{b}}$ Results are calculated at $95 \%$ confidence interval using the t-test $(\mathrm{t})$ and the standard deviation $(\mathrm{s})$ for the mean $(\bar{X})$ of a triplicate analysis $(\mathrm{N})$.

Table 4. Concentrations of lead in the roadside soils of Adama town.

\begin{tabular}{|c|c|c|c|c|c|c|c|c|}
\hline 产 & Sample sites & $\begin{array}{l}\text { Sample } \\
\text { code }\end{array}$ & $\begin{array}{c}\text { Distance } \\
(\mathrm{m})^{\mathrm{a}}\end{array}$ & $\begin{array}{l}\text { Traffic density } \\
\text { (No Car/h) } \\
\bar{X} \text { (range) }\end{array}$ & $\begin{array}{c}\mathrm{pH} \\
\left(25^{\circ} \mathrm{C}\right)\end{array}$ & $\begin{array}{l}\text { Cond. }(\mu \mathrm{S}) \\
\bar{X} \pm \mathrm{ts} \sqrt{\mathrm{N}} \\
\left(25^{0} \mathrm{C}\right)^{\mathrm{b}}\end{array}$ & $\begin{array}{c}\bar{X}_{(\mu \mathrm{g} / \mathrm{g})^{\mathrm{b}}}^{[\mathrm{Pb}]} \\
\pm \mathrm{ts} \sqrt{\mathrm{N}}\end{array}$ & $\begin{array}{c}\text { Average }[\mathrm{Pb}] \\
X^{ \pm} \pm \mathrm{ts} \sqrt{ } \mathrm{N} \\
(\mu \mathrm{g} / \mathrm{g})^{\mathrm{b}}\end{array}$ \\
\hline \multirow{11}{*}{ 莡 } & Alif & AD-1 & 1 & $973(946-998)$ & $6.64 \pm 0.12$ & $3200 \pm 3.0$ & $95.0 \pm 0.4$ & \multirow{3}{*}{$63.3 \pm 0.3$} \\
\hline & \begin{tabular}{|l|} 
Adama Soap \\
Factory
\end{tabular} & AD-2 & 0.5 & $829(803-846)$ & $7.25 \pm 0.14$ & $491 \pm 4.2$ & $41.5 \pm 0.5$ & \\
\hline & \begin{tabular}{|l|} 
Tikur-Abay \\
\end{tabular} & AD-3 & 0.75 & $784(725-805)$ & $7.19 \pm 0.13$ & $2000 \pm 11.4$ & $53.4 \pm 0.5$ & \\
\hline & Total & AD-4 & 1 & $\begin{array}{c}1196 \\
(1084-1224) \\
\end{array}$ & $7.17 \pm 0.18$ & $645 \pm 7.9$ & $70.8 \pm 0.2$ & \multirow[t]{3}{*}{$87.7 \pm 0.1$} \\
\hline & ELPA & $\mathrm{AD}-5$ & 0.75 & $\begin{array}{c}1466 \\
(1412-1485)\end{array}$ & $7.13 \pm 0.17$ & $2800 \pm 7.2$ & $113 \pm 0.2$ & \\
\hline & Gumruk & AD-6 & 1 & $\begin{array}{c}1370 \\
(1327-1404) \\
\end{array}$ & $7.63 \pm 0.20$ & $572 \pm 9.9$ & $78.3 \pm 0.2$ & \\
\hline & Post Office & AD-7 & 1 & $\begin{array}{c}2267 \\
(2226-2290) \\
\end{array}$ & $7.19 \pm 0.19$ & $277 \pm 7.0$ & $135 \pm 1.0$ & \multirow[t]{4}{*}{$88.5 \pm 0.3$} \\
\hline & Bus Station & AD-8 & 1.5 & $\begin{array}{c}2190 \\
(2145-2216) \\
\end{array}$ & $8.06 \pm 0.21$ & $339 \pm 7.7$ & $79.3 \pm 0.4$ & \\
\hline & \begin{tabular}{|l} 
Pan-Afric \\
Hotel
\end{tabular} & AD-9 & 1.5 & $\begin{array}{c}2079 \\
(2027-2100) \\
\end{array}$ & $7.13 \pm 0.16$ & $3200 \pm 6.2$ & $66.3 \pm 0.5$ & \\
\hline & $\begin{array}{l}\text { Unity } \\
\text { Surrounding }\end{array}$ & AD-10 & 2 & $\begin{array}{c}2162 \\
(2143-2286) \\
\end{array}$ & $8.40 \pm 0.14$ & $274 \pm 9.2$ & $73.9 \pm 0.3$ & \\
\hline & Control & $\mathrm{C}-3$ & 1000 & - & $7.70 \pm 0.19$ & $94 \pm 5.1$ & $20.8 \pm 0.8$ & $20.8 \pm 0.8$ \\
\hline
\end{tabular}

${ }^{\mathrm{a}}$ The distance is measured from the edge of the main road to the sampling points. ${ }^{\mathrm{b}}$ Results are calculated at $95 \%$ confidence interval using the t-test (t) and the standard deviation (s) for the mean $(\bar{X})$ of a triplicate analysis $(\mathrm{N})$.

From all the samples collected and studied, only four were found to contain lead concentrations above $100 \mu \mathrm{g} / \mathrm{g}$. These sites were: one from Bishoftu at the Old Bus Station $(108.8 \pm 0.7 \mu \mathrm{g} / \mathrm{g})$; the second from Modjo at the square to Ziway $(105 \pm 1.1 \mu \mathrm{g} / \mathrm{g})$; and the other two from Adama at Electric Power Agency $(113 \pm 0.2 \mu \mathrm{g} / \mathrm{g})$ and the Post Office $(135 \pm$ $1.0 \mu \mathrm{g} / \mathrm{g})$. The observed high lead concentrations of these four sites signified that the accumulation of lead in the roadside soils of the respective roads is most likely originated from 
vehicular emissions since there are no industrial activities around these areas. Besides, all of these sites are with the maximum traffic densities from each of their respective towns. This is further an indication for the effect of traffic density on the accumulation of lead on the roadside soils. In a similar study in Gazipur, Bangladesh, levels of lead in the roadside soils and vegetables along the major highways decreased with distance from the roads, indicating their linear dependence to the traffic density to the vehicular emissions [29].

Moreover, the four sampling sites, with average lead concentrations greater than the maximum recommended value by WHO, are located in the busy residential-commercial areas frequented by young children and outdoor workers which may increase the possibility for these individuals to be intoxicated by lead.

\section{Comparison of the lead concentrations in Modjo, Bishoftu and Adama Towns}

Although the three towns are found on the same road that connects the capital city with the southern and south eastern part of the country, some differences were observed in the concentration of lead accumulated in the roadside soils of the towns. Considering Adama, for example, two sampling sites, around Electric Power House and the site at the Post Office, showed lead concentration of $113 \pm 0.2$ and $135 \pm 1.0 \mu \mathrm{g} / \mathrm{g}$, respectively. The site around the Post Office is particularly with the maximum traffic density of the sampling sites considered in the present study as it is a junction where four roads from different directions intersect.

Considering the soil samples obtained from Bishoftu, those samples from the Old Bus Station were found to contain lead concentration of $109 \pm 0.7 \mu \mathrm{g} / \mathrm{g}$. In fact, this site may be expected to exhibit higher lead contaminations, as it is a point where various vehicles start and terminate their trips to/from different nearby towns. However, the openness of the areas may also have significant effects of distributing vehicular emissions away from their point source by wind $[1,6]$. Similarly, the openness of the sample sites in Modjo, together with the absence of big buildings, might have also contributed for the distribution of the lead from the vehicular emissions away from the roads. Here, the samples from the square to Ziway have shown a lead concentration of $105 \pm 1.1 \mu \mathrm{g} / \mathrm{g}$. This site is a junction for roads from three different directions where a large number of all types of vehicles travel to the southern part of the country. In order to clearly see the difference in the lead concentrations of the roadside soils of the three towns, the average lead concentrations versus the respective towns are plotted in Figure 4.

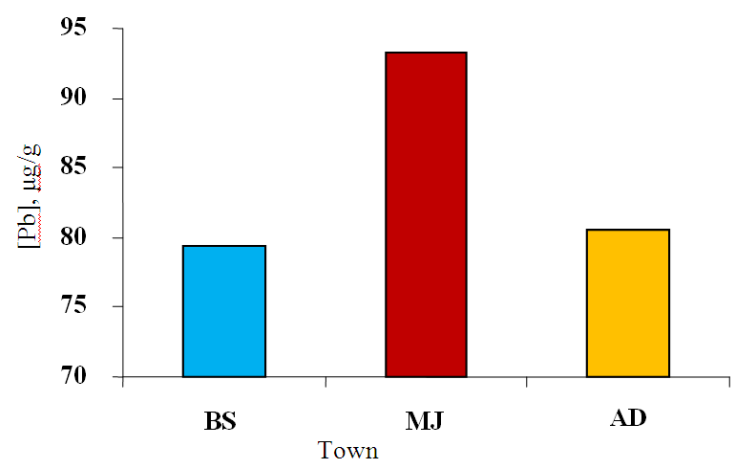

Figure 4. Comparison of the lead accumulation in roadside soils of Bishoftu (BS), Modjo (MJ) and Adama (AD) towns. 


\section{Determination of $\mathrm{pH}$ of the soil samples}

The chemical properties of lead in soil are directly related to $\mathrm{pH}$. In the present study, the ease of accessibility of lead in roadside soils to the plants and animals of the surrounding areas was investigated. The ranges for the $\mathrm{pH}$ values of the soil samples from Bishoftu, Modjo and Adama were found to be: $7.14 \pm 0.16$ to $7.74 \pm 0.17 ; 7.13 \pm 0.11$ to $7.31 \pm 0.21$; and $6.64 \pm 0.12$ to 8.4 \pm 0.14 , respectively. Complexation with organic matter, chemisorption on oxides and silicate clays and precipitation as carbonates, hydroxide or phosphate are all favored at higher $\mathrm{pH}$ and may decrease solubility of lead [30]. On the other hand, the availability of most of the trace metals added to the soil from different anthropogenic sources for plant uptake is directly related to the $\mathrm{pH}$. In near-neutral soils $(\mathrm{pH} 6-8)$ they are strongly bound and become more soluble in acidic soils ( $\mathrm{pH}$ less than 5). Thus, the cumulative effects of all these complex reactions may be responsible for the least mobility of lead in the soils, especially under non acidic conditions [31]. The findings in the present study may reveal that almost all the soil samples are within the neutral range $(6-8)$. Hence based on the observed $\mathrm{pH}$ values lead in the studied soils may be tightly bound to the soil and thus may not be easily accessible, especially to the plants.

\section{Determination of the electrical conductivities of the soil samples}

The electrical conductivities of the soil samples obtained from the three towns have been determined at $25{ }^{\circ} \mathrm{C}$. The measured results were found to be in the range: $384 \pm 6.0-2650 \pm$ 5.7; $306 \pm 6.5-4000 \pm 9.7$; and $274 \pm 9.2-3200 \pm 6.2 \mu \mathrm{S}$ (micro Siemens) corresponding to the soil samples of Bishoftu, Modjo and Adama towns, respectively. The observed results of this determination may imply that the soils form these sampling sites may be containing the amounts of lead enough to cause higher toxicities from limited (small) quantities of the soil samples [31]. Except for the soil samples obtained from the particular site of Modjo, at the square to Ziway, with the lead concentration of $105 \pm 1.1 \mu \mathrm{g} / \mathrm{g}$, the sample sites of Bishoftu and Adama with the lowest electrical conductivities were associated with lead concentrations of less than $100 \mu \mathrm{g} / \mathrm{g}$.

\section{Recovery and precision studies of the analytical method}

The percentage recoveries for the spiked soil samples of the three towns are given in Table 5, which were found to be in the range of $87.6-91.6$ and $89.4-92.8 \%$ for the 25 and $50 \mathrm{mg} / \mathrm{L}$ spiking levels, respectively. The observed results of the procedure utilized revealed the reliability and suitability of the method for further applications in quantitative extraction of lead from soil samples containing complex matrices. The precision of the method was determined by analyzing standard solution of lead at $10 \mathrm{mg} / \mathrm{L}$. The value of the relative standard deviation (RSD) for the seven replicate measurements which was found to be $3.6 \%$ signified the precision of the analytical method used in the current study.

Table 5. Recovery of spiked soil samples for the three towns $(n=3)$.

\begin{tabular}{|l|c|c|c|}
\hline Town & Spiked [Pb], $(\mathrm{mg} / \mathrm{L})$ & Obtained $[\mathrm{Pb}],(\mathrm{mg} / \mathrm{L})$ & Recovery $\%$ \\
\hline \multirow{3}{*}{ Modjo } & 0 & 13.5 & - \\
\cline { 2 - 4 } & 25 & 35.7 & 88.8 \\
\cline { 2 - 4 } & 50 & 59.9 & 92.8 \\
\hline \multirow{3}{*}{ Bishoftu } & 0 & 19.6 & - \\
\cline { 2 - 4 } & 25 & 41.5 & 87.6 \\
\hline \multirow{3}{*}{ Adama } & 50 & 64.3 & 89.4 \\
\cline { 2 - 4 } & 0 & 20.8 & - \\
\cline { 2 - 4 } & 25 & 43.7 & 91.6 \\
\hline
\end{tabular}

Bull. Chem. Soc. Ethiop. 2014, 28(2) 
Variation of the lead levels in the roadside soils with traffic density

To correlate the lead contents of the roadside soils with the traffic density of the corresponding roads, the traffic densities of all the sample sites in the three towns were investigated. This analysis was carried out by counting the number of all types of vehicles that pass a point at a given road for one hour ( 9 - 10 AM) for three successive days and the average was taken (Tables 2-4). At the sampling sites located in the relatively enclosed areas of higher atmospheric stability, lead contents increased markedly with increasing traffic density. However, the distribution of lead in the roadside soils revealed different patterns, in the absence of such atmospheric stability, which has been attributed mainly to the effect of meteorological factors such as wind [32, 33].

Literature reports have also indicated that there is a direct proportionality between the concentration of lead in the roadside soils and the traffic volume of the roads. According to the study done in Venezuela [34], the concentration of lead in leaves and roots of plants sampled at heavy traffic roadsides was higher than in the samples from a light traffic sites. Similarly, studies on the concentrations of lead in roadway dust and roadside plants from the metropolis of Pune and Maharashtra (India) have shown that the enrichment of dust and plants with lead is closely related to the density of vehicular traffic. The areas with higher density of vehicular traffic have shown higher concentrations of lead in the roadway dust [35].

In the present study, the correlations between lead concentrations of roadside soils and the traffic density of the corresponding roads for all of the three towns were evaluated using the Pearson coefficient of correlation. Using this method, the observed correlations between the two variables are presented as follows: $\mathrm{r}(4)=0.82, \mathrm{p}<0.05$ for Modjo; $\mathrm{r}(5)=0.32, \mathrm{p}<0.05$ for Bishoftu; and r $(9)=0.81, \mathrm{p}<0.05$ for Adama. The findings of the current study indicated the existence of a strong positive or direct correlation between the two variables for Modjo and Adama roadside soils while a moderate positive correlation for Bishoftu. The relationship between the traffic densities of the sampling sites and the corresponding average lead concentrations for the three towns has been described in Figures 5-7.

Comparison of lead contents of this study with other studies

The lead concentrations determined in the present study were compared with the lead levels for various towns reported in the literature (Table 6). As can be seen in Table 6, the levels of lead in Riyad [36], was the highest followed by Addis Ababa [37], Northern England [38], Jordan [39] and Dare es Salaam [40]. These values are higher than the values of lead for all the three towns, Modjo, Bishoftu and Adama considered in the current study. However, the lead concentrations obtained for towns in Gazipur [29], Aurangabad [41] and Jos Metropolis [42] were lower than the three towns of this study.

\section{Contamination factor $(C F)$}

The level of contamination of soils by the metal is expressed in terms of a contamination factor (CF) given below:

$\mathrm{CF}=\left(\mathrm{C}_{\mathrm{m}}\right.$ Sample $) /\left(\mathrm{C}_{\mathrm{m}}\right.$ Background $)$

where $\mathrm{C}_{\mathrm{m}}$ Sample is the concentration of the metal in the samples analyzed and $\mathrm{C}_{\mathrm{m}}$ Background is the metal concentration in the control sample. The contamination factor, $\mathrm{CF}<1$ refers to low contamination, while $1 \leq \mathrm{CF}<3$ indicates moderate contamination. Furthermore, $3 \leq \mathrm{CF} \leq 6$ indicates considerable contamination and $\mathrm{CF}>6$ indicates very high contamination [43]. 
$\mathrm{Pb}$ accumulation in roadside soils from heavy density motor way towns of eastern Ethiopia 173

Accordingly, the contamination factors for the average lead concentration of Modjo, Bishoftu and Adama towns were found to be 6.9, 3.96 and 3.84, respectively. The contamination factors show that the roadside soil of Modjo, $\mathrm{CF}>6$, is highly contaminated while those of Bishoftu and Adama, $3 \leq \mathrm{CF} \leq 6$, are with considerable contamination.

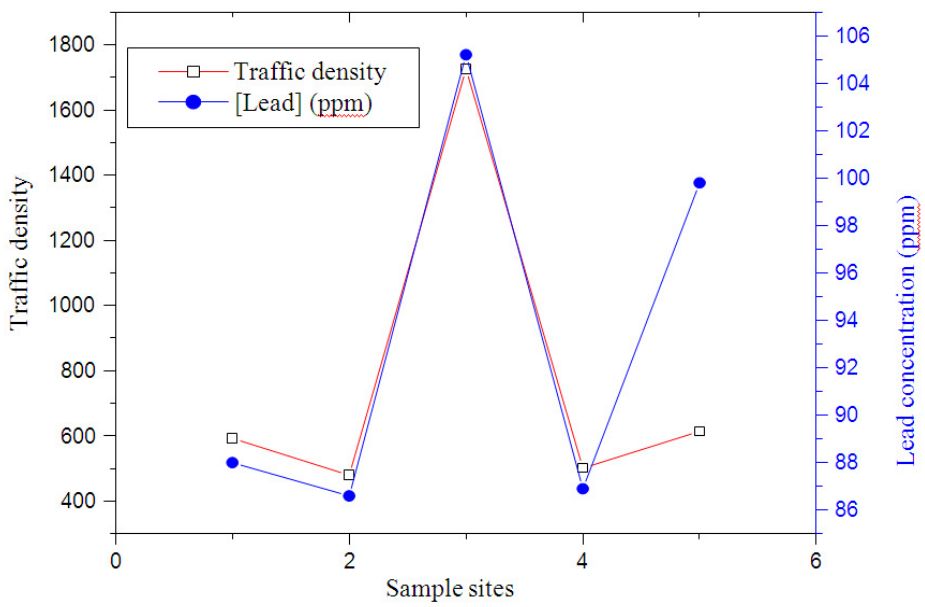

Figure 5. Variation of lead concentrations with traffic densities of the corresponding sampling sites in Modjo town.

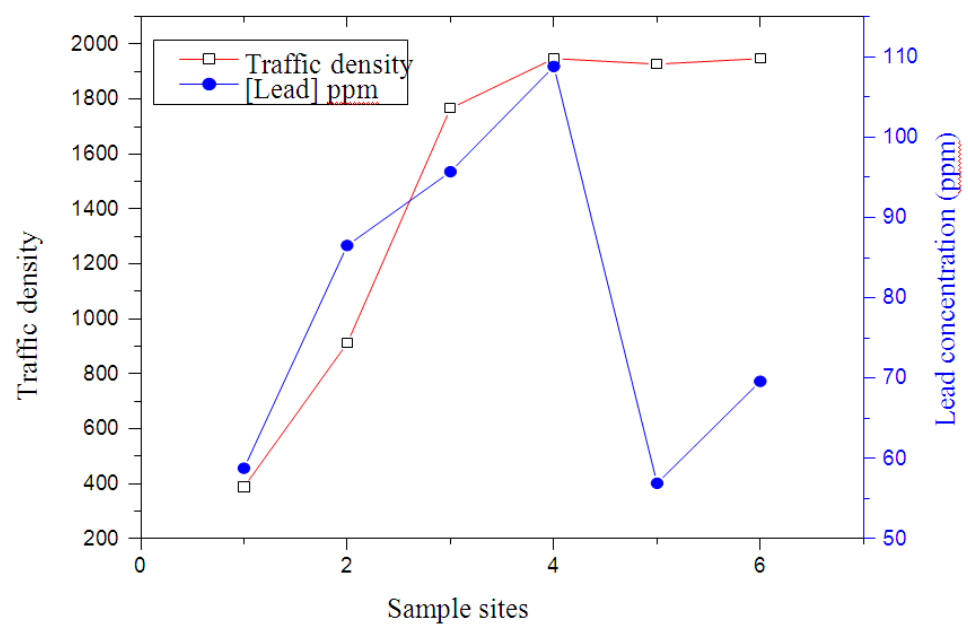

Figure 6. Variation of lead concentrations with traffic densities of the corresponding sampling sites in Bishoftu town. 


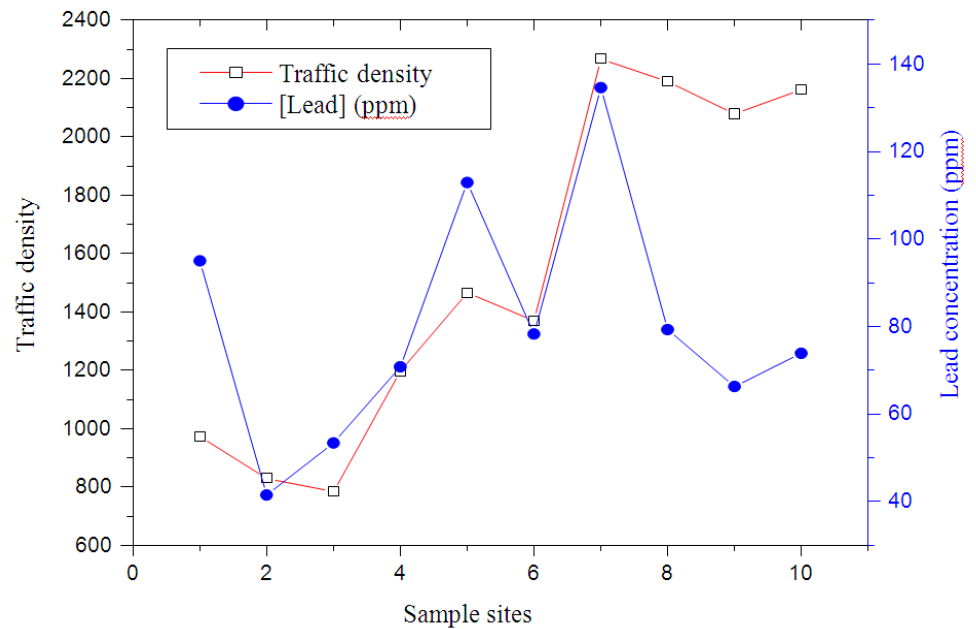

Figure 7. Variation of lead concentrations with traffic densities of the corresponding sampling sites in Adama

Table 6. Comparison of lead concentration for the three towns, Modjo, Bishoftu and Adama with other studies in the literature.

\begin{tabular}{|c|l|c|c|}
\hline No & Town & {$[\mathrm{Pb}], \mu \mathrm{g} / \mathrm{g}$} & Ref. \\
\hline 1. & Gazipur, Bangladesh & 20.8 & {$[29]$} \\
\hline 2. & Riyadh, Saudi Arabia & 461 & {$[36]$} \\
\hline 3. & Addis Ababa, Ethiopia & 419 & {$[37]$} \\
\hline 4. & Northern England & 233 & {$[38]$} \\
\hline 5. & Jordan & 189 & {$[39]$} \\
\hline 6. & Dar es Salaam, Tanzania & 153 & {$[40]$} \\
\hline 7. & Aurangabad, India & 27.2 & {$[41]$} \\
\hline 8. & Jos Metropolis, Nigeria & 12.1 & {$[42]$} \\
\hline 9. & Modjo, Ethiopia & 93.3 & This study \\
\hline 10. & Bishoftu, Ethiopia & 77.7 & This study \\
\hline 11. & Adama, Ethiopia & 79.8 & This study \\
\hline
\end{tabular}

\section{CONCLUSIONS}

The levels of lead accumulation in the roadside soils of three towns of Eastern Ethiopia, viz., Bishoftu, Modjo and Adama were investigated by collecting soil samples from representative sampling sites.

Results of the current study demonstrated that the traffic volume caused a significant increase in lead contents in roadside soils. This was clearly shown by the difference in the lead concentrations between the roadside soil samples and that of the background control samples. Higher lead concentrations were found for the sampling sites with higher traffic volume on the main roads. On average, the soil samples from Modjo town indicated higher lead concentrations, which may be attributed to the fact that Adama is the center of commercial and social activities than Modjo and Bishoftu. Except for the sampling sites with new soil covers and for those with the windy meteorological conditions, the concentrations of lead correlated 
with the traffic density of the roads. The openness of most of the roads in the present study could also have significant effect on the tendency of the aerosols from vehicular emission not to reside on the roadside soils.

In general, the main source of lead in roadside soils of the three towns is mainly from the use of lead additives in gasoline. It is believed to originate from the previous use of leaded gasoline, as $\mathrm{Pb}$ could persist in the soil environments thus having long term effects. It is to be noted that the gasoline imported and distributed by the Ethiopian Petroleum Enterprise nowadays is nearly lead free or may contain negligible quantities of lead.

\section{ACKNOWLEDGEMENTS}

The Swedish International Development Agency and the Department for Research Cooperation (SIDA/SAREC) are greatly appreciated for the financial support received through the pesticide research project. Instrumental facilities for successful accomplishment of this project have been provided by the Department of Chemistry of Addis Ababa University.

\section{REFERENCES}

1. Naveed, N.H.; Batool, A.I.; Rehman, F.U.; Hameed, U. Afr. J. Environ. Sci. Technol. 2010, 4,770 .

2. Zhao, Y.X.; Ding, M.Y.; Chen, D.P. Anal. Chim. Acta 2005, 542, 193.

3. Singh, V.; Chandel, C.P.S. J. Environ. Sci. Eng. 2006, 48, 103.

4. Marqués, M.J.; Salvador, A.; Morales-Rubio, A.E.; Guardia, M.D. Fresenius J. Anal. Chem. 2000, 367, 601.

5. Mendoza, C.A.; Cortes, G.; Muiioz, D. Environ. Toxicol. Water Qual. 1996, 11, 327.

6. John, W.H.; Alex, W.H. Environ. Toxicol. Water Qual. 1997, 12, 245.

7. Thomas, V.; Kwong, A. Energy Policy 2001, 29, 1133.

8. Lin, T.; Tai-yi, J. Environ. Toxicol. 2007, 22, 229.

9. Franck, U.; Herbarth, O.; Langer, O.; Stark, H.J.; Treide, A. Environ. Toxicol. 1999, 14, 439.

10. Ekong, E.B.; Jaar, B.G.; Weaver, V.M. Kidney Int. 2006, 70, 2074.

11. Garcia-Fernandez, A.; Martinez-Lopez, J.E.D.; Maria-Mojica, R.P.; Godino A.; Jimenez, P. Environ. Toxicol. 2005, 20, 459.

12. Khalil, N.; Wilson, J.W.; Talbott, E.O.; Morrow, L.A.; Hochberg, M.C.; Hillier, T.A.; Muldoon, S.B.; Cummings, S.R.; Cauley, J.A. Environ. Health 2009, 8, 1.

13. Maria, A.; Kevin, A.; Jolly, W.; Pingitore, N.E. J. Blood Med. 2010, 1, 71.

14. Lovi, M. Phasing out lead from gasoline: Worldwide experiences and policy implications: World Bank technical paper no 397; 1998.

15. Sharma, S.; Prasad, F.M. E-J. Chem. 2010, 7, 1174.

16. Oztas, T.; Sibel, A. Int. J. Environ. Pollut. 2002, 18, 190.

17. Schirnding, Y.E.R.; Fuggle, R. F. Sci. Total Environ. 1996, 187, 1.

18. Gzyl, J. Sci. Total Environ. 1990, 96, 199.

19. Ho, Y.B. Sci. Total Environ. 1990, 93, 411.

20. P. Bultynck, World Bank: Phase-out of leaded gasoline in oil importing countries of SubSaharan Africa. The case of Ethiopia Action plan: Clean air working paper number 13: ESMAP Technical report number $03803 ; 2003$.

21. Chimuka, L.; Mugwedi, R.; Moboladisoro, B.H.; Odiyo, O.J. Water SA 2005, 31, 581. 
22. Westbom, R.; Hussen, A.; Megersa, N.; Retta, N.; Mathiasson, L.; Bjorklund, E. Chemosphere 2008, 72, 1181.

23. Vandecasteele, C.; Block, C.B. Modern Methods for Trace Element Determination, John Wiley \& Sons: UK; 1993.

24. VanLoon, J.C. Selected Methods of Trace Metal Analysis - Biological and Environmental Samples, John Wiley \& Sons: USA; 1985.

25. Odiyo, J.O.; Bapela, H.M.; Mugwedi, R.; Chimuka, L. Water SA 2005, 31, 581.

26. Fifield, F.W.; Kealey, D. Principles and Practice of Analytical Chemistry, Blackwell Science Ltd: UK; 2000.

27. Louella, F.O.; Annie, M.P.A.; Jacqueline A.P.; Gilbert, C.S. Environ. Sci. Pollut. Res. 2006, 13, 177.

28. Naser, H.M.; Sultana, S.; Gomes, R.; Noor, S. Bangladesh J. Agri. Res. 2012, 37, 9.

29. Genc, A.; Ulupinar, E. Transp. Porous Media 2010, 84, 699.

30. McBride, M.B. Environmental Chemistry of Soils, Oxford University Press: USA; 1994.

31. Itana, F. Bull. Chem. Soc. Ethiop. 1998, 12, 105.

32. Al-Muzaini, S.; Jacob, P.G. Environ. Toxicol. Water Qual. 1996, 11, 285.

33. Farooq, H.; Jamil, Y.; Ahmad, M.R.; Khan, M.A.A.; Mahmood, T.; Mahmood, Z.; Zia-ulH.; Khan, S.A. J. Basic Appl. Sci. 2012, 8, 463.

34. Elizabeth, O. Braz. J. Plant Physiol. 2003, 15, 149.

35. Bharati, P.D.; Dnyan, P.N.; Venkat, G.R. Biologia Indica 1992, 1, 43.

36. Al-Shyeb, S.M.; Seaward, M.R.D. Asian J. Chem. 2001, 13, 407.

37. Teju, E.; Megersa, N.; Chandravanshi, B.S.; Zewge, F. SINET: Ethiop. J. Sci. 2012, 35, 81.

38. Akbar, K.F.; Hale, W.H.G.; Headley, A.D.; Athar, M. Soil Water Res. 2006, 1, 158.

39. Jaradat, Q.M.; Moman, K.A. Turk. J. Chem. 1999, 23, 209.

40. Luilo, G.B.; Othman, O.C. Tanz. J. Sci. 2006, 32, 61.

41. Asif, S.; Abed, S.; Farooqui, M. Adv. Appl. Sci. Res. 2011, 2, 371.

42. Abechi, E.S.; Okunola, O.J.; Zubairu, S.M.J.; Usman, A.A.; Apene, E. J. Environ. Chem. Ecotoxicol. 2010, 2, 98

43. Mmolawa, K.B.; Likuku, A.S.; Gaboutloeloe, G.K. Afr. J. Environ. Sci. Technol. 2011, 5, 86. 